\title{
A AUDIODESCRIÇÃO DOS SENTIMENTOS DAS PERSONAGENS NO FILME UM AMIGO INESPERADO
}

\author{
Janaína Vieira Taillade Abud (UECE)* \\ Renata de Oliveira Mascarenhas (UECE)**
}

\section{RESUMO}

Este artigo apresenta parte dos resultados do Projeto CAD_TV (PosLA/UECE/BFPFUNCAP), que, por meio de um estudo baseado em corpus, descreveu as estratégias de tradução de roteiros de audiodescrição (AD) de programas exibidos na televisão brasileira. Nessa perspectiva, o presente trabalho objetiva analisar as estratégias discursivas utilizadas no roteiro de AD do filme Um Amigo Inesperado (2006) para recriar os sentimentos das personagens. Para isso, as seguintes etapas foram realizadas: (1) solicitação da gravação do programa junto à emissora; (2) transcrição da $\mathrm{AD}$ em software específico; (3) etiquetagem do roteiro de AD; (4) revisão das etiquetas; (5) identificação das recorrências narrativo-discursivas; (6) descrição e análise das recorrências mais significativas; e (7) comparação das estratégias discursivas das inserções de AD com as imagens do filme. Foram consideradas, neste estudo, apenas as etiquetas referentes à classificação das emoções das personagens, no caso, estado emocional, estado mental e expressão facial. De modo geral, a análise evidenciou um paralelismo entre signos visuais da obra e signos verbais do roteiro de AD. No nível gramatical-discursivo, percebeu-se uma tendência à inversão de termos da oração, estratégia que atribuiu destaque às informações relativas aos sentimentos das personagens.

Palavras-chave: Tradução audiovisual acessível. Audiodescrição. Linguística de corpus. Narratologia fílmica.

\section{ABSTRACT}

\section{THE AUDIO DESCRIPTION OF CHARACTERS' FEELINGS IN THE FILM AFTER THOMAS}

This article presents part of the results from CAD_TV (PosLA/_UECE/ BFP-FUNCAP) research project that, through a corpus based study, described the translation strategies in audio description scripts of programs broadcast on Brazilian television. In this perspective, the present work aims to analyse the discursive strategies in the audio description script of the movie After Thomas (2006) in order to recreate the expression of feelings among characters. In this sense, the following steps have been taken: (1) request of the audio described program of the broadcast; (2) transcription of the audio

\footnotetext{
* Mestranda em Linguística Aplicada pela Universidade Estadual do Ceará (UECE). Pesquisadora do Grupo de Pesquisa Tradução e Semiótica do Programa de Pós-Graduação em Linguística Aplicada da Universidade Estadual do Ceará. E-mail: janataillade@gmail.com

** Doutora em Letras pela Universidade Federal da Bahia (UFBA). Pesquisadora do Grupo de Pesquisa Tradução e Semiótica do Programa de Pós-Graduação em Linguística Aplicada da Universidade Estadual do Ceará. E-mail: renamasc@hotmail. com
} 
description using a specific software; (3) labelling of the AD script; (4) review of the labels; (5) identification of narrative-discursive recurrence in the scripts; (6) description and analyses of meaningful recurrence; and (7) comparison of the discursive strategies in the AD inserts with their correspondent movie images. In the present study, only the labels related to the classification of characters' emotions were considered: emotional states, mental states and facial expressions. In general, the study revealed a parallel between visual movie signs and verbal signs in the AD script. In the grammaticaldiscursive level, it was noticed a clear tendency to invert the standard word position in a sentence, highlighting information related to a characters' feelings.

Keywords: Audiovisual translation and accessibility. Audio description. Corpus linguistics. Film narratology.

\section{RESUMEN}

\section{AUDIODESCRIPCIÓN DE LOS SENTIMIENTOS DE LOS PERSONAJES EN LA PELÍCULA UN AMIGO INESPERADO}

Este artículo presenta parte de los resultados del proyecto CAD_TV (PosLA/ UECE/BFP/FUNCAP) que, por medio de un estudio basado en corpus, describió las estrategias de traducción de guiones de audiodescripción (AD) de programas exhibidos en la televisión brasileña. La presente investigación objetiva analizar las estrategias discursivas utilizadas en el guión de AD de Un amigo inesperado (2006) para recrear los sentimientos de los personajes. Para ello, las siguientes etapas fueron realizadas: (1) grabación del programa junto a la emisora; (2) transcripción de la AD en software específico; (3) etiquetado del guión de $\mathrm{AD}$; (4) revisión de las etiquetas; (5) identificación de las recurrencias narrativo-discursivas; (6) descripción y análisis de las recurrencias más significativas; y (7) comparación de las estrategias discursivas de las inserciones de AD con las imágenes de la película. Han sido consideradas solamente las etiquetas referentes a la clasificación de las emociones de los personajes, estado emocional, estado mental y expresión facial. El análisis ha evidenciado un paralelismo entre signos visuales de la obra y signos verbales del guión de AD. En el nivel gramatical-discursivo, se ha percibido una tendencia a la inversión de términos de la oración, estrategia que ha atribuido destaque a las informaciones relativas a los sentimientos.

Palabras clave: Traducción audiovisual accesible. Audiodescripción. lingüística de corpus. Narratología fílmica.

\section{Introdução'}

A ausência de acessibilidade das produções artísticas às pessoas com deficiência visual (PcDVs) se configura como um tipo de exclusão social. No

1 Agradecemos a colaboração do Setor de Acessibilidade da TV Aparecida, que disponibilizou o referido produto audiodescrito e seu respectivo roteiro de audiodescrição, o auxílio da Fundação Cearense de Apoio ao Desenvolvimento Científico e Tecnológico por meio do Programa de Bolsas de Fixação de Pesquisador, bem como a contribuição de bolsistas e voluntários envolvidos no Projeto de Pesquisa CAD_TV, a saber: Sofia Amoreira, Renatta Franco, Ana Carla Ponte, Alexandra Seoane, Ana Tássia Silva e Lindolfo Farias Júnior. intuito de reverter essa questão, a audiodescrição (AD), recurso de natureza linguística que verbaliza qualquer informação visual, vem se consolidando como ferramenta capaz de conferir a autonomia necessária para a PcDV usufruir de todos os bens culturais e educacionais no seu entorno.

No contexto audiovisual brasileiro, a Portaria $\mathrm{n}^{\mathrm{o}} 188$, de 24 de março de 2010, estabelece um cronograma para implantação da $\mathrm{AD}$ na programação das emissoras abertas de radiodifusão de sons 
e imagens. Assim, a referida portaria institui um mínimo de duas horas semanais de programação audiodescrita. Além disso, estabelece que esse tempo deverá aumentar gradualmente, em um prazo de 11 anos, até que sejam transmitidas 20 horas semanais (BRASIL, 2010).

Tomando como base essa determinação legal, o projeto Acessibilidade na televisão brasileira: a construção e a análise de um corpus de roteiros de audiodescrição da grade de programas da TV aberta - CAD_TV (BFP-FUNCAP/PosLA-UECE), ao qual o presente artigo está vinculado, teve por objetivo "mapear e descrever as estratégias de tradução de base narratológico-imagético-discursivas dos roteiros de audiodescrição de filmes e seriados exibidos" na programação de emissoras da TV aberta, "atentando para as especificidades das categorias dos programas e dos seus respectivos gêneros" (PROJETO CAD_TV, 2013,p. 17). Como escopo teórico, a pesquisa utilizou a proposta de Jimenez Hurtado e colaboradores (2007, 2010). Entre os 24 programas analisados no projeto, foi escolhido como corpus para o presente trabalho o filme Um Amigo Inesperado (UM AMIGO..., 2006), do gênero drama, audiodescrito e exibido pela TV Aparecida.

Vale ressaltar que, dentro do CAD_TV, outros gêneros fílmicos foram abordados em estudos anteriores por Nóbrega (2015) e Seoane (2015), trabalhos estes que também analisaram diferentes aspectos discursivos e narratológicos, dentre os propostos pelo projeto. Nóbrega (2015) analisou dois filmes do gênero animação infantil, sob o recorte das descrições do ambiente. Já Seoane (2015) analisou seis filmes de gêneros diferentes, focando na presença ou não de descrição das características físicas das personagens e de como esta acontece.

Ambos os trabalhos dialogam com o presente estudo pelo fato de utilizarem a mesma metodologia e porque têm como base teórica uma análise discursiva e narratológica, baseada nos estudos fílmicos. No entanto, o diferencial proposto aqui é ampliar para o nível imagético a discussão realizada até então. Outro aporte novo é enfocar o gênero drama.

Dessa forma, este trabalho tem como objetivo geral analisar as estratégias discursivas para traduzir os recursos narratológico-imagéticos do filme Um Amigo Inesperado, levando em conta o gênero da obra. Já seus objetivos específicos são: investigar quais parâmetros discursivo-narratológico-imagéticos podem ser extraídos do roteiro de audiodescrição do referido filme e verificar em que medida o gênero drama influenciou na audiodescrição estudada. Para tanto, são apresentados a seguir alguns princípios teóricos que fundamentam este estudo.

\section{Audiodescrição e narrativa audiovisual}

Com base na nomenclatura de Jakobson (1995), posteriormente ampliada por Plaza (2013), a audiodescrição (AD) é considerada uma modalidade de tradução de natureza intersemiótica, uma vez que consiste na interpretação de signos visuais para signos verbais orais. Nessa perspectiva, ela compreende um tipo de Tradução Audiovisual Acessível (TAVa) que visa garantir o acesso de pessoas com deficiência visual a qualquer produção (audio)visual.

Quanto ao processo de elaboração, a AD decorre da criação de um roteiro prévio que é posteriormente gravado ou narrado ao vivo, dependendo do seu campo de aplicação. No caso de filmes exibidos na televisão, objeto deste estudo, a narração do roteiro é sempre gravada e mixada à trilha sonora do filme, de maneira que as estruturas discursivas do roteiro devem ser cuidadosamente selecionadas, tendo em vista a função do conteúdo visual e os intervalos entre os diálogos e os efeitos sonoros do filme. Nesse contexto, o roteiro de audiodescrição de um filme deve levar em conta os mesmos princípios da narrativa audiovisual (e do cinema em particular).

Ao estabelecer um paralelo entre um filme e sua respectiva audiodescrição, Mascarenhas (2012, p. 73 ) argumenta que os mesmos princípios da narratologia audiovisual podem "direcionar a identificação dos elementos mais expressivos de composição dos personagens principais, bem como orientar as escolhas discursivas e a distribuição da informação no roteiro de AD." Segundo ela:

No processo tradutório de audiodescrição, pautando-se nas convenções textuais dos gêneros narrativos, deve-se buscar identificar as saliências dos elementos de composição do texto fonte no intuito de recons- 
truir para o público com deficiência visual os efeitos sensoriais e emocionais programados pelos realizadores das obras. (MASCARENHAS, 2012, p. 39).

De acordo com Mascarenhas (2012, p. 44), para se chegar a uma compreensão do processo tradutório que implica a audiodescrição de um filme, é preciso levar em conta todos os elementos narratológicos da obra, como "[...] a linguagem da câmara (planos, ângulos, movimentos) e os elementos do discurso audiovisual (montagem e efeitos)". Para a pesquisadora, o mapeamento das escolhas discursivas do roteiro de AD deve organizar "[...] na mesma categoria, a linguagem audiovisual, a sua função comunicativa e os elementos narrativos." (MASCARENHAS, 2012, p. 44)

Nesse contexto, o presente trabalho busca verificar se há, no objeto estudado, essa correspondência entre a narratologia fílmica (por meio de ângulos, planos e sequências) e a narrativa composta pelos elementos verbais da audiodescrição analisada. No entanto, para se obter dados consistentes e aptos à discussão, utilizou-se a linguística de corpus, cuja apresentação e explicação é objeto da próxima seção.

\section{Audiodescrição e linguística de corpus}

Segundo Silva (2012), desde os anos 1950 as pesquisas linguísticas vêm utilizando como suporte teórico-metodológico a linguística de corpus. Neste âmbito, esta última tem servido a diversos propósitos que vão desde a elaboração de dicionários até aulas de língua estrangeira, passando pelos estudos de tradução e, especificamente, pelos estudos de Tradução Audiovisual (TAV). Berber Sardinha (2004 apud SILVA, 2012) define linguística de corpus como a coleta e a exploração de corpora (conjunto de dados linguísticos textuais coletados criteriosamente), com a finalidade de pesquisar uma língua ou uma variedade linguística, com base em evidências empíricas, extraídas por computador.

Entre os pesquisadores que utilizam essa metodologia aplicada aos estudos de TAV, estão Payá (2010) Jiménez Hurtado (2007, 2010) e Salway (2007). Entre as vantagens dessa metodologia está a possibilidade de gerar dados empíricos e analisar grande quantidade desses dados com precisão. Payá
(2010) argumenta em favor da análise baseada em corpus como base científica sólida na investigação de textos multimodais, como é o caso de filmes audiodescritos. Na sua avaliação, essa metodologia permite a estruturação de corpora de qualquer tipo de texto, sendo estes confiáveis, a partir do momento em que colecionam textos reais e representativos de uma classe textual. Ela também ressalta a importância da análise de roteiros de AD segundo essa metodologia, diante do crescimento do interesse em acessibilidade nos meios audiovisuais.

Silva (2012,p. 29) explica que "[...] os trabalhos de Jiménez Hurtado et al. (2007, 2010), Ballester (2007) e Salway (2007) demonstram o alcance de aplicação da linguística de corpus nas pesquisas em tradução e mais especificamente na tradução audiovisual". Silva (2012) destaca o pioneirismo dos estudos citados na aplicação da linguística de corpus na análise de audiodescrição. Os referidos estudos enfatizam a necessidade de se preparar os textos estudados com etiquetas que servirão como parâmetro para levantamento dos dados quantitativos. Tais etiquetas "[...] são definidas de acordo com os objetivos de cada pesquisa." (SILVA, 2012, p. 30).

Dentro dos estudos que utilizam a linguística de corpus para análise de roteiros de audiodescrições fílmicas, Jiménez Hurtado (2010) propõe três tipos de etiquetas, nos níveis narratológicos, cinematográficos (linguagem de câmera) e gramatical-discursivos. Para a pesquisadora, analisar um corpus pelo viés desses níveis de estudo permite estabelecer comparações e buscar parâmetros e equivalências entre os filmes e as audiodescrições. A autora parte da concepção de que os filmes audiodescritos são estruturas multimodais.

As etiquetas de natureza narratológica propostas por Jiménez Hurtado (2010) abrangem três eixos fundamentais da narrativa fílmica: ações, ambientes e personagens. Entre as etiquetas que Jiménez Hurtado (2010) propõe para a caracterização dos personagens estão: apresentação, identificação, atributos físicos (idade, etnia, aspecto, vestuário, expressão facial e linguagem corporal) e estados (emocional, físico e mental). O Projeto CAD_TV retoma Jiménez Hurtado (2010) e adapta suas etiquetas ao corpus de AD de filmes exibidos pela TV brasileira, abrangendo, conforme proposto por 
Jiménez Hurtado, não somente personagens, mas também inserções textuais, aspectos da ambientação e ação.

Payá (2010) discute as etiquetas pautadas na linguagem cinematográfica, que viabilizam um cotejo da linguagem imagética com a tradução de seus efeitos nos roteiros de audiodescrição. Seu trabalho define os significados narratológicos dos planos, ângulos, posições de câmera, movimentos de câmera e transições. Ela relaciona esses recursos imagéticos com a linguagem da audiodescrição.

A referida autora, a partir de Casetti y Di Chio (1991 apud PAYÁ, 2010), considera que o texto fílmico pode ser dividido em cena, em quadro e em série. Desta forma, as etiquetas propostas por ela contemplaram os códigos mais convencionais e reconhecidos em termos de linguagem fílmica, $o$ que correspondeu aos mais traduzidos no roteiro de AD. Em seu estudo, Payá (2010) verificou que as inserções de $\mathrm{AD}$ descreviam as imagens por planos e cenas e que mantinham recorrências discursivas que correspondiam ao discurso cinematográfico. Por exemplo, planos gerais tendiam, no roteiro de $\mathrm{AD}$, a corresponder a descrições que iam do geral ao particular. Já primeiros planos correspondiam a informações específicas e subjetivas das personagens, como emoções, pensamentos e estados de ânimos.

Os trabalhos de Mascarenhas (2012), Jiménez Hurtado (2010) e Payá (2010) se complementam, traçando um caminho para a discussão proposta no presente estudo, como parte do CAD_TV. Parte-se do conceito de que o gênero narrativo da obra e seus elementos de composição influenciam nas escolhas discursivas do roteiro de AD (MASCARENHAS, 2012). Retoma-se as ideias de Jiménez Hurtado (2010) das três estruturas narrativas a serem levadas em conta em uma correspondência com a $\mathrm{AD}$ : nível narratológico, nível cinematográfico ou da linguagem de câmera e nível gramatical-discursivo. Por fim, busca-se replicar o estudo de Payá (2010) e identificar no texto multimodal escolhido a colocação em quadro e colocação em série e sua possível correspondência com a $\mathrm{AD}$. Na próxima seção, indo mais adiante nas propostas de Jiménez-Hurtado e Payá, afunila-se o recorte na recriação das personagens por meio da audiodescrição, objeto do presente estudo.

\section{A recriação das personagens cinematográficas via audiodescrição}

Jiménez Hurtado (2010) afirma que as personagens se apresentam por meio de suas ações, dos ambientes em que atuam, dos seus recursos físicos e emocionais. Para ela, pensamentos, atitudes, emoções e sentimentos estruturam as personagens e as identificam. Por isso, ela propõe que a macroetiqueta personagem se subdivida em subetiquetas: apresentação, identificação, atributos físicos, estados emocionais (positivos e negativos), estados físicos e estados mentais. Neste trabalho, escolheu-se analisar os aspectos mentais e sentimentais, por meio das etiquetas: estado emocional, estado mental e expressão facial, por entender que são as três que melhor descrevem as emoções das personagens.

Acredita-se que fica óbvia a relação entre as etiquetas de estado mental e emocional, com esse aspecto dos sentimentos. No entanto, a escolha da expressão facial merece uma pequena explicação. Quando aborda as etiquetas de personagem, Jiménez Hurtado (2010) destaca que as emoções são frequentemente descritas de maneira indireta, de forma que a expressão facial revela este aspecto. Para a pesquisadora, "a relação cognitiva entre sentimento e expressão facial é sempre próxima, já que o sentimento se traduz por meio do olhar". ${ }^{2}$ (JIMÉNEZ HURTADO, 2010, p. 85).

A autora também afirma que a linguagem da câmera se reflete no roteiro de $\mathrm{AD}$, com uma espécie de sintaxe e de estrutura semântico-cognitiva. Ela aponta um triângulo cognitivo formado pelas categorias de percepção, movimento e emoção como o primeiro padrão semântico-sintático presente no roteiro de audiodescrição, em que as emoções são o motor fundamental das ações dramáticas. Nesse sentido, no roteiro de AD a descrição dos sentimentos acompanha o verbo como predicativo, caracterizando uma tematização, segundo os conceitos da Linguística Sistêmico Funcional (LSF) de tema (informação principal) e rema (informação complementar).

2 "La relación cognitiva entre sentimiento y expresión facial es siempre próxima ya que el sentimiento se traduce a través de la mirada em lo que Salway denomina el evento del foco de atención." 
Já Payá (2010), como já foi dito, amplia a análise de Jiménez Hurtado (2010), no aspecto da interface filme e AD. Para entender os códigos fílmicos, ela retoma a ideia de Casetti e Chio (1991 apud PAYÁ, 2010) da divisão em cenas, quadros e séries. Payá (2010) define a colocação em cenas como a organização do conteúdo da imagem, posição espacial dos elementos cênicos diante da câmera. A colocação de quadros seria o tipo de enquadramento, o ângulo, o movimento e a duração. Por sua vez, a colocação em série é a sequência de planos por meio da montagem, convertendo a história em discurso ou trama.

De uma forma geral, Payá (2010) percebe uma correspondência entre os quadros e a importância dada na frase da $\mathrm{AD}$ a certos elementos, alterando a ordem habitual sujeito-verbo-objeto, operando o que ela chama, com base da Linguística Sistêmico Funcional (LSF), de tematização (colocação em destaque) ou rematização (colocação em segundo plano) de determinados componentes. Ela também assinala para o uso de conectores temporais e espaciais na $\mathrm{AD}$ que correspondem à colocação em série, dando coesão ao texto da $\mathrm{AD}$ de forma intratextual (entre as inserções) e extratextual (da AD com os outros elementos do filme audiodescrito). Ela também observa que primeiros planos coincidem com descrição de expressão facial ou de vestuário.

Prosseguindo no seu paralelo entre a $\mathrm{AD}$ e o filme, Payá (2010) define três funções básicas da $\mathrm{AD}$ que correspondem, segundo ela, a funções do discurso fílmico: descrever, narrar, analisar e assinalar. Assim, o Grande Plano Geral e o Plano Geral são usados para descrever. Os Planos Inteiro, Americano e Médio têm como função principal narrar e fazer a ação avançar. Já o Primeiro Plano analisa os pensamentos e estados de ânimo das personagens, enquanto o Plano de Detalhe assinala ao espectador um detalhe ou informação que ele precisa memorizar para acompanhar o relato.

Indo mais além no paralelismo com a $\mathrm{AD}$, o Grande Plano Geral e o Plano Geral têm como função descrever o lugar, tematizando essa informação espacial, além de construir a coesão com a cena anterior. Os Planos Inteiro e Americano narram a postura corporal, o vestuário e os movimentos em cena. O Plano Médio e o Primeiro
Plano analisam a linguagem corporal, a expressão facial, os olhares e a psicologia. O Plano de Detalhe assinala uma metonímia e contribui para a coesão da história.

Por outro lado, o ângulo e o lugar da câmera marcam pontos de vistas e correspondem a perspectivações, evidência dos dispositivos cinematográficos (terminologia cinematográfica), ou mudanças no tema-rema. Movimentos de câmera descrevem ou narram, marcam pontos de vistas, conectam os espaços, sendo traduzidos verbalmente na evidência dos dispositivos cinematográficos, complemento circunstancial de lugar, verbos de percepção etc. Modos de filmagem e fotografia criam uma linguagem poética, simbólica e emotiva, traduzindo-se em evidência do dispositivo cinematográfico e orações subordinadas.

Na colocação em série, as transições fazem uma pausa narrativa ou uma elipse, sendo traduzidos por conectores discursivos temporais e espaciais. O ritmo de montagem tem uma função emotiva e é traduzido por locuções e prosódia. Já os diversos usos de montagem servem para narrar, associar ou contrapor, sendo traduzidos com orações reflexivas, conectores discursivos espaciais ou temporais, repetições lexicais, comparações/metáforas, orações subordinadas, verbos de cognição e evidência do dispositivo cinematográfico.

Como o foco deste estudo é a descrição das emoções e dos sentimentos das personagens, dentro da perspectiva apresentada por Payá (2010), parecem se destacar o Plano Médio e o Primeiro Plano. O Plano Médio delimitando, segundo a autora, a fronteira entre os planos narrativos e expressivos e servindo para mostrar as ações e interações das personagens, ao mesmo tempo em que permite observar os traços do rosto, as expressões, as reações e os olhares, assim como a linguagem corporal. Já o Primeiro Plano, de acordo com a pesquisadora, é utilizado em cenas com grande carga emocional e retrata a psicologia da personagem, centrando em emoções, pensamentos e expressões faciais. Ela observa que o Primeiro Plano frequentemente se utiliza da técnica de plano-contraplano. Lembrando que esses planos podem ser combinados com outros efeitos já citados.

$\mathrm{Na}$ análise proposta aqui, busca-se verificar os resultados obtidos por Payá (2010) com relação 
à correspondência entre as técnicas de narrativa imagética dos filmes e os recursos empregados na $\mathrm{AD}$, como forma de tradução dessas imagens. No entanto, para se aprofundar na discussão desse paralelo, assim como dos outros aspectos já colocados, outra abordagem se revela valiosa, a de compreender a relação entre o gênero fílmico, no caso um drama, e a construção da audiodescrição correspondente.

\section{O gênero drama e a audiodescrição}

O gênero de um filme implica em efeitos programados, tanto na película original quanto na audiodescrição do filme. Nesse sentido, partindo da poética do audiovisual proposta por Gomes (2004 apud MASCARENHAS, 2012):

O procedimento de análise de um produto audiovisual deve partir da identificação de emoções e sensações previstas sobre a apreciação do público-alvo, para então se chegar às estratégias e aos mecanismos que as geram, analisando, assim a estrutura que as fundamentam. (MASCARENHAS, 2012, p. 191).

Segundo Mascarenhas (2012, P. 56), o gênero se reflete na $\mathrm{AD}$, pois:

As narrativas audiovisuais ficcionais são compostas de sequências de efeitos programados capazes de provocar expectativas e inferências por parte da recepção, cabendo ao tradutor/audiodescritor, portanto, inicialmente detectar os referidos efeitos [...].

Sob outro enfoque, mas reforçando a importância do gênero, o Dicionário de Comunicação (BARBOSA, 2001, p. 134) destaca a essencialidade dos gêneros no cinema e dá uma visão geral da abrangência e da diversidade de gêneros cinematográficos.

O cinema, 'sétima arte', impunha-se pelo constante avanço técnico, como mercadoria cultural e como nova dramaturgia, nova expressão artística abrangendo vários gêneros e tendências (documentário, épico, drama e melodrama, western, guerra e resistência, horror, ficção científica, policial, musical, publicitário, jornalístico, político etc.) e os mais variados estilos.

Os filmes, portanto, encaixam-se em um determinado gênero, sob várias óticas como: a iconografia, os temas, a narrativa, os atores ou o diretor.
Assim, estudar sob a perspectiva do gênero envolve olhar para um filme sob o prisma dos códigos e das convenções dados pelo gênero, por um lado, e das expectativas da audiência, por outro. Ferreira (2003, p. 6) assim define o gênero fílmico: “[...] um instrumento útil para a análise dos filmes: é um sistema de códigos, convenções e estilos visuais que possibilita ao público determinar rapidamente e com alguma complexidade o tipo de narrativa que está assistindo".

Para Aumont e Marie (2008, p. 87), as convenções de gêneros existem, mas podem ser quebradas, podem evoluir no tempo ou pode-se "brincar" com elas: "Como é evidente, um filme pode sempre jogar com essas 'obrigações' ou combiná-las; algumas alianças entre gêneros foram muito férteis [...]".

Partindo da essencialidade dos gêneros na sétima arte, é importante entender um pouco o gênero do filme ora analisado: um drama familiar.

O gênero drama é muito amplo, abrangendo quase todos os filmes que combinam um roteiro sério com personagens verossímeis. As histórias contam dramas que mexem com as personagens, à medida que estas enfrentam conflitos externos e internos.3 (GROSVENOR, 2016, tradução nossa).

Dramas são frequentemente biografias de pessoas reais ou fictícias. Alguns enveredam por temas sérios como política, doenças, drogas e relacionamentos. "A situação conflitiva, geralmente de cunho psicológico, comportamental ou de relacionamento interpessoal compõe o leitmotiv do filme. O drama [...] constitui o cinema por excelência, justamente por enfocar a problemática humana". (BILHARINHO, 1996 apud FERREIRA, 2003, p. 6).

Sendo um drama familiar o objeto deste estudo, é preciso entender que se trata de um subgênero do gênero drama que tem como característica específica enfocar personagens que formam uma família.

Outro gênero que demonstra ser interessante de se abordar nessa fundamentação teórica é o melodrama, que, segundo Melo (2005, p. 15), tem no relato das emoções no seio da família seu cenário

3 "The drama genre is wide, encompassing almost any movie that combines a serious plot with believable characters. The stories told in dramas revolve around the characters themselves as they face conflicts, both external and internal." 
ideal: "A afetividade familiar cabe bem ao melodrama, pois seu fácil reconhecimento não precisa de maiores explicações, e é de geral empatia pelos espectadores". As emoções expressas dentro da família são elevadas a virtudes ou pecados.

Outra particularidade desse melodrama é a recusa da vida doméstica ordinária. O ordinário é o lugar de significação, onde nossa vida rotineira tem um valor maior que o que aparenta, e em que o lar é campo de batalha no qual lutamos pela felicidade. (MELO, 2005, p. 20).

Vale ressaltar que as personagens de filmes (tema deste trabalho) são marcadas pelo gênero ao qual pertencem. Como explica Mascarenhas (2012), as personagens são construídas para desempenhar funções específicas com relação ao espectador, conforme o gênero fílmico. O gênero direciona a construção das personagens:

Um dos fatores que direciona tal construção é o gênero de narrativa, de modo que uma comédia, um drama ou um suspense, por exemplo, tende a representar em suas particularidades categóricas, personagens com densidade psicológica, caracterizações e atuações distintas. Assim, costuma-se verificar numa comédia romântica, por exemplo, personagens psicologicamente menos complexos se comparados aos personagens de um drama familiar ou de um suspense de assassino em série. (MASCARENHAS, 2012, p. 60).

Mascarenhas (2012) prossegue na análise, afirmando que tudo em uma personagem contribui para a trama, desde ações, sentimentos até a aparência, passando pelo que as outras personagens dizem dela. Bal (1997 apud MASCARENHAS, 2012) reafirma a importância da recepção na construção das personagens, que, segundo ele, depende do conhecimento de mundo do espectador ou da postura desse espectador diante da obra que ele interpreta. Mais uma vez, é onde entra a previsibilidade (que funciona como indício) que interage com o conhecimento prévio que o espectador tem do gênero que está assistindo.

A previsibilidade facilita a coerência na conexão de um personagem com eventos da história, contribui para a formação de uma imagem uniforme do mesmo dentre um aglomerado de informações da narrativa e agiliza o reconhecimento e as inferências do re- ceptor sobre tais personagens. (MASCARENHAS, 2012, p. 63).

Outra informação valiosa é que cada personagem vai se construindo com o decorrer da trama, precisando para isso, por exemplo, que haja repetições das características marcantes, de forma a enfatizá-las.

Tanto as características das personagens próprias do gênero, como a presença delas ao longo da trama, quanto as repetições necessárias para o espectador construí-las em sua imaginação encontram reflexo no roteiro de $\mathrm{AD}$, como fruto do processo tradutório. Mascarenhas (2012, p. 73) explicita isso:

Para a elaboração do roteiro de audiodescrição, a análise descritiva desses princípios pode direcionar a identificação dos elementos mais expressivos de composição dos personagens principais, bem como orientar as escolhas discursivas e a distribuição da informação no roteiro de $\mathrm{AD}$.

Concluída a exposição dos referenciais que norteiam este trabalho, a seguir são apresentados seus aspectos metodológicos.

\section{Metodologia}

Esta pesquisa é descritiva, baseada em corpus, pois propõe reflexões sobre os aspectos narratológicos-imagéticos-discursivos no roteiro de audiodescrição em português do filme Um Amigo Inesperado (UM AMIGO..., 2006), tomando como base uma análise eletrônica do roteiro preparado por etiquetagem. Quanto à natureza, trata-se de um estudo quali-quantitativo. Em seu aspecto quantitativo, a pesquisa identifica a frequência dos dados presentes no corpus. Em seu aspecto qualitativo, são analisados esses dados, conforme a base teórica escolhida.

Este trabalho está inserido no projeto Acessibilidade na televisão brasileira: a construção e a análise de um corpus de roteiros de audiodescrição da grade de programas da TV aberta (PROJETO CAD_TV, 2013, p. 17), vinculado ao Programa de Pós-Graduação em Linguística Aplicada da Universidade Estadual do Ceará (PosLa/UECE), cujo objetivo é "mapear e descrever as estratégias de tradução de base narratológico-imagético-dis- 
cursivas dos roteiros de audiodescrição de filmes e seriados" exibidos na grade de programação de três emissoras, "atentando para as especificidades das categorias dos programas e dos seus respectivos gêneros". O projeto tem como corpus 24 programas, sendo oito filmes de diferentes gêneros narrativos exibidos na Globo, oito episódios do seriado Chaves exibidos no SBT, assim como quatro episódios do seriado Hermanas e quatro filmes exibidos na TV Aparecida.

O presente estudo consiste num recorte do Projeto CAD_TV no que diz respeito tanto ao corpus quanto aos aspectos analisados. Com relação ao corpus, busca-se analisar o roteiro de AD de um filme do gênero drama familiar exibido pela TV Aparecida. Quanto aos aspectos analisados, dentre as categorias narratológicas adotadas pelo projeto, este trabalho se propõe a analisar apenas a categoria de caracterização das personagens referente à expressão de sentimentos.

O filme audiodescrito Um Amigo Inesperado (After Thomas, no original), que compõe o corpus deste estudo, foi traduzido e, posteriormente, exibido pela TV Aparecida em 15 de dezembro de 2013. Trata-se de uma produção inglesa de Beryl Vertue e Elaine Cameron, sob a direção de Simon Shore e escrita por Lindsey Hill, lançada em 2006 e com duração de 93 minutos (1h33min).

A narrativa apresenta a rotina do casal Nícola (Keeley Hawes) e Rob (Ben Miles), cujo filho Kyle (Andrew Byrne), de cinco anos, é autista. No início da trama, a criança tem o comportamento afetado por sua dificuldade em se comunicar, o que causa transtornos à relação de afeto em todo o núcleo familiar. Enquanto o pai acredita que Kyle deveria ir para um colégio interno especializado em crianças especiais, a mãe insiste em criar o filho em casa. A mudança na trama acontece quando o casal decide adotar um filhote de cachorro da raça Golden Retreiver, que é batizado de Thomas pelo próprio Kyle. Na convivência com o animal de companhia, Kyle passa, aos poucos, a se abrir para a interação com outras pessoas, chegando a expressar sentimentos complexos, como o amor pelos pais.

$\mathrm{O}$ roteiro de $\mathrm{AD}$ do filme Um Amigo Inesperado foi elaborado pelo Setor de Acessibilidade da própria da TV Aparecida. A equipe dedicada à audiodescrição, na emissora, é composta por duas roteiristas, uma narradora e um editor, sob a coordenação de Flávia Machado.

O referido roteiro de $\mathrm{AD}$, composto por 6.719 palavras divididas em 510 inserções de descrição, foi etiquetado pelos integrantes do projeto CAD_TV com 53 tipos de etiquetas referentes a elementos narrativos, com base nas categorias narratológicas propostas por Jimenez-Hurtado (2007, 2010): personagens, ambientes, ações, subtítulos, sinais, escritos, títulos e créditos. Somente para a categorização de descrição das personagens foram 16 etiquetas diferentes, das quais apenas três serão consideradas para o objetivo deste estudo, a saber: estado emocional $<$ PERS_EEMOC $>$, estado mental $<$ PERS_EMENT $>$ e expressão facial $<$ PERS_EXPFAC $>$.

Com relação aos procedimentos metodológicos, seguindo o padrão adotado para todo o corpus do projeto CAD_TV, o roteiro de AD foi, primeiramente, transcrito a partir do Subtitle Workshop 2.51, software gratuito de marcação e edição de legendas, que possibilitou: a transposição do roteiro de $\mathrm{AD}$ para o formato de arquivo .srt com as respectivas marcações de tempo de entrada e saída de cada inserção de $\mathrm{AD}$, bem como a visualização das transcrições das inserções sobre as imagens do filme. Após essa etapa, o roteiro de $\mathrm{AD}$ foi etiquetado manualmente a partir do programa Bloco de Notas e posteriormente salvo como documento do Word para a revisão coletiva do roteiro etiquetado. Diante do caráter subjetivo de classificação de algumas etiquetas, o grupo de pesquisa adotou o seguinte procedimento: o roteiro de $\mathrm{AD}$ foi transcrito e etiquetado por um integrante; em seguida, as etiquetas foram revisadas por outra pessoa, que fez os devidos ajustes e comentários quando pertinentes; posteriormente, todo o grupo de pesquisa analisou coletivamente os comentários do revisor visando à aprovação final do corpus etiquetado.

Depois da criação do corpus etiquetado, utilizou-se o programa de análise linguística WordSmith Tools 6.1 (WS Tools), especificamente sua ferramenta Concord, com a finalidade de identificar as estratégias discursivas mais recorrentes no roteiro para descrever as emoções das personagens. Para isso, o arquivo do roteiro de 
AD etiquetado foi convertido para o formato .txt com o intuito de ser reconhecido pelo software em questão. Assim foi possível contabilizar o valor absoluto das etiquetas analisadas, analisar seu cotexto completo e quantificar as palavras que se repetiam nas inserções. O resultado dessa análise é apresentado a seguir.

\section{Descrição e discussão das estratégias de tradução dos sentimentos expressos pelas personagens}

Em termos quantitativos, o corpus estudado apresenta um total de 87 etiquetas relativas à descrição dos sentimentos dos personagens, sendo 51 etiquetas para estado emocional, 23 para estado mental e 13 para expressões faciais. A seguir apresenta-se uma descrição quanti-qualitativa das estratégias discursivas utilizadas para traduzir cada categoria (etiqueta) analisada.

\section{Estado emocional}

A etiqueta $<$ PERS_EEMOC $>$ identifica o fragmento de audiodescrição que traduz os estados emocionais das personagens. Normalmente, ela classifica o verbo, o adjetivo ou a locução adjetiva que descreve a emoção da personagem em cada ação dramática.

A quantificação da referida etiqueta entre as personagens no filme demonstra que Nícola (mãe) é a personagem mais caracterizada em termos de estado emocional, com 21 ocorrências de etiquetas $<$ PERS_EEMOC $>$. Em seguida, destaca-se Rob (pai) com 16 ocorrências. Na sequência, as emoções do casal (os dois juntos) são descritas seis vezes e as do menino Kyle, cinco vezes. As demais ocorrências descrevem as emoções de personagens secundárias, como: uma senhora na rua (1); Rachel, uma amiga de Rob (1); e Phil, um parente (1).

A escolha lexical mais recorrente é o adjetivo "sério", que ocorre 12 vezes, e sua forma feminina "séria", identificada uma vez. O referido adjetivo é a única escolha lexical para qualificar a protagonista Kyle (5) e também qualifica seis vezes o estado emocional do pai, o que, possivelmente, representa, respectivamente, a falta de empatia do garoto com relação ao seu entorno e a apreensão do pai quanto à postura do filho.

Outras escolhas mais frequentes para caracterizar o estado emocional das personagens são: "emocionado" (4) / "emocionada" (2), "sem graça" (4) e "lágrimas" (4). Este substantivo é observado em expressões como: "Com lágrimas nos olhos, Nícola se afasta. (AD208); "Lágrimas começam a escorrer pelo rosto de Nícola." (AD 443); “Lágrimas surgem nos olhos de Nícola e Rob olha para ela." (AD 499); e "Sorrindo e, com lágrimas nos olhos, o casal se observa." (AD 388). As escolhas lexicais mais frequentes tendem a representar, de modo geral, a relação de empatia e afetuosidade dos pais com relação ao filho.

Dentre as escolhas lexicais menos frequentes, destacam-se: "aflita" (2); "desesperada" (2), "surpresos" (2); "preocupados" (1); "cabisbaixo" (1); "suplicante" (1); "constrangida" (1). Todas com campo semântico negativo, representando o estado de inquietação e desconforto das protagonistas diante do drama familiar.

Em termos de estrutura discursiva, verifica-se que, das 51 ocorrências da etiqueta $<$ PERS_EEMOC $>, 37$ aparecem no início e 13 no decorrer da inserção. $\mathrm{O}$ Quadro 1 apresenta os esquemas e alguns exemplos das estruturas discursivas mais frequentes.

Quadro 1 - Estruturas mais frequentes para a etiqueta $<$ PERS_EEMOC $>$

\begin{tabular}{|c|c|}
\hline $\begin{array}{l}\text { Início da } \\
\text { inserção }\end{array}$ & $\begin{array}{c}\text { SENTENÇA SIMPLES: } \\
\text { ADJUNTO ADNOMINAL (adjetivo ou expressão) + SUJEITO (substantivo ou } \\
\text { pronome pessoal ou sujeito composto ou artigo seguido de substantivo) + VERBO + } \\
\text { COMPLEMENTO }\end{array}$ \\
\hline
\end{tabular}




\begin{tabular}{|c|c|}
\hline \multicolumn{2}{|l|}{ Exemplo: } \\
\hline AD73 & $<$ PERS_EEMOC $>$ Sério, ele larga as cartas em um canto e vai até Kyle. \\
\hline AD502 & $<$ PERS_EEMOC $>$ Emocionado, Rob coloca a mão sobre ombro da esposa. \\
\hline AD208 & $<$ PERS_EXPFAC $><$ PERS_EEMOC $>$ Com lágrimas nos olhos, Nícola se afasta. \\
\hline $\begin{array}{l}\text { Meio da } \\
\text { inserção }\end{array}$ & $\begin{array}{l}\text { SENTENÇA COMPLEXA com COORDENADA ADITIVA: } \\
\text { ADJUNTO ADNOMINAL (adjetivo) ou COMPLEMENTO CIRCUNSTANCIAL } \\
\text { DE MODO (expressão) + SUJEITO + VERBO + COMPLEMENTO }\end{array}$ \\
\hline \multicolumn{2}{|l|}{ Exemplos: } \\
\hline AD469 & Todos olham para Kyle e, $<$ PERS_EEMOC $>$ sério, Phil coloca sua taça na mesa. \\
\hline AD421 & $\begin{array}{l}\text { Ele olha para o filho e, }<\text { PERS_EEMOC }>\text { com os olhos embargados, volta a olhar } \\
\text { a esposa. }\end{array}$ \\
\hline
\end{tabular}

Fonte: Elaborado pelas autoras deste artigo.

Conforme o Quadro 1 ilustra, as etiquetas de $<$ PERS_EEMOC $>$ identificadas tanto no início quanto no meio das inserções normalmente classificam um termo da oração que sofreu inversão. Os estados emocionais descritos no meio da inserção estão presentes em orações coordenadas e posicionados no início da segunda oração, estratégia discursiva que atribui realce aos sentimentos das personagens envolvidas na ação dramática. Nesse sentido, verifica-se que a tradução de Um Amigo Inesperado opta, de modo recorrente, pela anteposição do adjunto adnominal ao sujeito, alterando, assim, a sequência mais usual dos termos da oração, ou seja, a ordem direta da sentença. Conforme abordado por Payá (2010), com base na Linguística Sistêmico Funcional (LSF), isso caracteriza a tematização ou colocação em destaque das informações relativas ao estado emocional.

$\mathrm{Na}$ Língua Portuguesa, normalmente, essa ordem direta se estabelece pela seguinte organização: o sujeito, seguido de verbo, de complementos e, finalmente, de expressões adverbiais. A inversão dessa ordem busca enfatizar algum termo da oração. $\mathrm{O}$ uso deste recurso linguístico, muitas vezes, tem como finalidade privilegiar o aspecto subjetivo da linguagem. No caso das inserções de AD exemplificadas no quadro acima, observa-se que a mera anteposição dos adjuntos adnominais aos sujeitos das sentenças dá maior destaque aos estados emocionais das personagens. Nesse sentido, aparentemente, a subjetividade atribuída ao discurso audiodescritivo por meio das inversões identificadas nos exemplos vai ao encontro da carga dramática das suas respectivas cenas.

Mediante essa breve descrição e exemplificação das estruturas discursivas mais recorrentes para a etiqueta $<$ PERS_EEMOC $>$, propõe-se, a seguir, a partir da proposta de Payá (2010), a análise comparativa de um dos exemplos supracitados com suas respectivas imagens (quadro a quadro), com o intuito de verificar possíveis correspondências entre a informação imagética da obra (escolhas de planos e montagem) e o conteúdo verbal do roteiro de audiodescrição.

Nessa perspectiva, o Quadro 2 apresenta as imagens referentes à inserção de AD502, em que se observa um plano médio seguido de um primeiro plano. 
Quadro 2 - Comparação quadro a quadro entre as imagens do filme e a AD502

CONTEXTO: Esta sequência retrata o momento em que, após uma doença, o cachorro Thomas se restabeleceu. Em um parque, o casal passeia com Kyle e Thomas. Ao se aproximar de um labirinto feito de cerca viva, o menino corre com o cachorro e desaparece da vista dos pais. Rob corre atrás deles enquanto Nícola os acompanha de longe. Quando todos se reúnem novamente, Kyle comenta que Thomas não está mais doente. Kyle também fala que ama a mãe dele. O casal se emociona, pois é a primeira vez que o menino expressa algum sentimento pelos pais. Nícola pede para o menino repetir e o abraça. Antes de mostrar o abraço, nesta sequência analisada, o filme foca no rosto de Nícola emocionada e, em seguida, no rosto de Rob olhando surpreso para ela. Somente então há a aproximação da mãe em direção ao filho, aparecem os rostos dos pais juntos e finalmente o abraço. Esta cena dialoga com outra, anterior, quando a família está reunida na praia e Nícola se queixa de que o Kyle a odeia e Rob responde que Kyle não odeia, mas também não ama, porque "ele não sabe o que são sentimentos". Rob então afirma: "Ele nunca vai amar você".

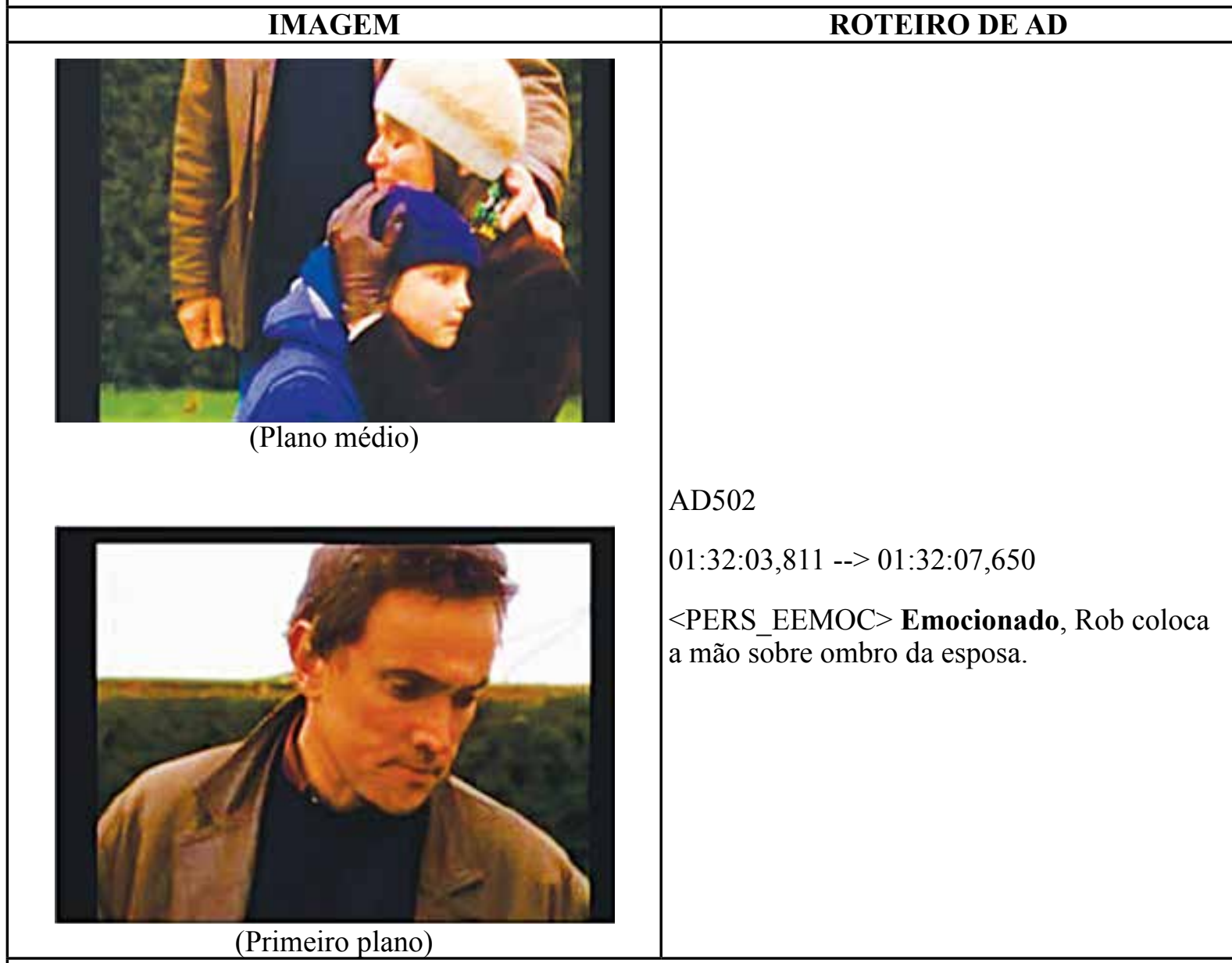

AD do quadro 2: Neste quadro, visualiza-se a comparação entre as imagens do filme e a inserção de AD502. $\mathrm{Na}$ coluna da esquerda, vê-se a sequência de imagens do filme, enquanto, na da direita, mostra-se o texto da AD correspondente. Na sequência de duas imagens, observa-se, primeiro, Nícola ajoelhada e abraçando Kyle, enquanto Rob apoia sua mão no ombro da esposa e, segundo, vê-se Rob emocionado olhando para os dois. Na coluna direita, lê-se: "Emocionado, Rob coloca a mão sobre ombro da esposa."

Fonte: Elaborado pelas autoras deste artigo. 
Verifica-se, nesse exemplo, que há uma relativa correspondência entre a função da linguagem da câmera e a audiodescrição. O plano médio, cuja função é retratar ações e emoções dos personagens, mostra a mão de Rob sobre o ombro da esposa, enquanto esta abraça o filho. Em seguida, o primeiro plano, em que há o foco no rosto de Rob, apresenta em detalhes as emoções da personagem. A análise da estratégia discursiva da inserção AD 502 comparada à função da imagem indica que, no referido exemplo, a descrição verbal inverte a ordem de montagem, no entanto, por meio da inversão do adjunto adnominal "emocionado" para o início da oração, consegue recriar a ênfase dramática da cena. Os resultados da categoria (etiqueta) ora analisada corroboram Payá (2010), pois conferem a relação estabelecida pela autora entre a linguagem fílmica e o discurso audiodescritivo.

\section{Estado mental}

A etiqueta $<$ PERS_EMENT $>$ classifica adjetivos ou advérbios que se referem ao estado mental das personagens. No roteiro analisado, esse tipo de descrição é mais frequente para a personagem Rob (11 vezes), pai de Kyle, seguido da mãe Nícola (9 vezes). O menino Kyle é descrito como "atento" apenas uma vez. A professora do Kyle é qualificada de "confusa" uma vez, e a mãe da Nícola como "desacordada", uma vez.

Essa concentração das descrições de estado mental nas personagens Rob e Nícola parece coerente com seus respectivos protagonismos na trama sentimental do filme. O roteiro de AD analisado, portanto, reflete o gênero drama familiar, centrado no casal protagonista e sua relação com o filho. $\mathrm{O}$ fato de Kyle, apesar de protagonista, não ser muito descrito nesse aspecto possivelmente decorre da sua caracterização como personagem autista, de maneira que suas emoções só têm dois estados: um mais constante, de seriedade; outro menos frequente, de fúria.

Com relação às escolhas lexicais, somente os adjetivos "pensativa" e "pensativo" aparecem, respectivamente, seis e cinco vezes. Depois disso, a maior ocorrência é da palavra "atento", que é utilizada duas vezes. As demais palavras que são usadas segundo essa classificação apresentam apenas uma ocorrência, como: "atenta", "cansado", "confuso", "confusa", "impaciente", "exausta", "acordado", "adormecido", "desacordada" e "atentamente".

Ao se observar o cotexto de ocorrência das etiquetas, verifica-se que a maioria classifica interação do casal entre si ou dos pais com o filho. Nesse sentido, identifica-se um padrão semântico-discursivo, em relação à descrição dos estados mentais, atrelado ao tema central da narrativa, de modo que as reações de Rob e Nícola estão normalmente no campo da apreensão e do esgotamento diante da rotina com o filho.

No que diz respeito à estrutura discursiva das etiquetas de estado mental no roteiro de $\mathrm{AD}$, foram encontradas 23 ocorrências, sendo 14 vezes no início e nove no meio da inserção. A estrutura mais frequente apareceu 13 vezes, sempre no início da inserção, como pode ser visualizada no Quadro 3

Quadro 3 - Estrutura discursiva mais recorrente para a etiqueta $<$ PERS_EMENT $>$

\begin{tabular}{|l|}
\hline \multicolumn{2}{|c|}{ SENTENÇA SIMPLES ou PRINCIPAL COM SUBORDINADA } \\
ADJUNTO ADNOMINAL OU MINISSENTENÇA (adjetivo) + SUJEITO (substantivo ou pronome \\
pessoal ou artigo + substantivo) + VERBO+ COMPLEMENTO \\
\hline Exemplos: \\
\hline AD179
\end{tabular}

Fonte: Elaborado pelas autoras deste artigo. 
A partir dos exemplos apresentados no Quadro 3 , verifica-se uma tendência à inversão da posição habitual do adjetivo, que vai para uma colocação em destaque no início da frase, ao invés de estar ao lado do substantivo. Essa posição em início de frase tematiza o elemento da oração deslocado, como aponta Payá (2010). Segundo a concepção de Castilho (2014), quando o adjetivo é núcleo de minissentença, ele pode predicar o sujeito, o objeto direto ou indireto ou o sintagma verbal. Essa descrição enfatiza ainda mais sua importância na sentença.

A seguir, uma análise comparativa de uma inserção exemplificada no quadro 3 com as suas respectivas imagens. De forma geral, o que se constata é que há uma correspondência relativa entre as imagens e o texto verbal. No exemplo do quadro 4, observa-se novamente um plano médio, propício a descrições do estado mental.

Quadro 4 - Comparação quadro a quadro entre as imagens do filme e a AD179

CONTEXTO: A cena analisada faz parte da apresentação do conflito entre as personagens Rob e Nícola, tendo como pano de fundo a tomada de uma decisão sobre o melhor destino para Kyle: se em um colégio interno especializado ou se em casa com os pais. Na cena, a família está preparando o aniversário de Rob. $\mathrm{Na}$ cozinha de sua casa, Nícola desabafa com a mãe, Pat, sobre uma discussão com Rob. Pat tenta apaziguar, afirmando que a solução está em conversar. Nícola também conta o quanto se sente culpada em relação a Kyle e, nesse momento, entra a irmã de Rob, Kate. Nícola interage com Kate.

(Plano médio)
(PERS_EMENT > Pensativa, ela olha para as
mulheres.

Fonte: Elaborado pelas autoras deste artigo. 
Nesse exemplo escolhido para análise da etiqueta $<$ PERS_EMENT $>$, o que se vê é certa correspondência da $\mathrm{AD}$ com as imagens. A diferença entre o filme original e o com audiodescrição é que, no primeiro, o vidente só tem acesso, neste momento, à imagem de Nícola da cintura para cima, com olhar atento. Essa imagem em plano médio de Nícola complementa a sequência de imagens anterior que mostrava, primeiro, Pat e Kate na cozinha ao lado de Nícola, todas em plano médio, e, em seguida, Pat e Kate saindo do campo da tela.

Diferentemente, a audiodescrição se refere à cena completa (que o vidente apenas pode inferir) em que se veria as interlocutoras e Nícola em pontos opostos da cozinha. Em teoria, em uma correspondência supostamente mais exata (seguindo o pensamento de Payá), a cena completa descrita pela AD corresponderia a um plano mais aberto, talvez um plano geral, seguido de um plano médio. Para compreender melhor a sequência, vale descrever que, nos quadros seguintes, o diretor optou pela sequência plano/contraplano, pois após a imagem de Nícola, em contraplano, vê-se Kate e Pat do outro lado da cozinha.

Apesar dessa divergência na adaptação feita pela $\mathrm{AD}$, quanto às escolhas lexicais, observa-se uma correspondência quando há destaque no estado mental, com a tematização de "pensativa". Pode-se perceber que o diretor escolheu o plano médio, que segundo Payá (2010), corresponde bem à descrição dos sentimentos das personagens, sendo propícia a uma carga emocional.

\section{EXPRESSÃO FACIAL}

A etiqueta referente à expressão facial $<$ PERS EXPFAC $>$ de uma personagem, no roteiro analisado, geralmente, classifica um verbo, um adjetivo ou uma locução adjetiva. De modo geral, como observado nas categorias previamente discutidas, verifica-se que as descrições das expressões faciais das personagens se concentram no pai Rob e na mãe Nícola, sendo o número de repetições oito e cinco vezes, respectivamente. As demais personagens não são caracterizadas desta forma. Assim, foram encontradas apenas 13 ocorrências dessa etiqueta, sendo cinco no início da inserção e oito no decorrer da inserção. Acredita-se que a baixa ocorrência dessa etiqueta possa estar relacionada a uma maior preferência pela qualificação direta das emoções apresentadas do que pela sugestão detalhada dos movimentos da face. Estratégia que se contrapõe a prescrições de alguns manuais de $\mathrm{AD}$, mas que se revela eficiente na economia de tempo para inserções rápidas comuns em filmes.

Quanto às escolhas lexicais do roteiro de $\mathrm{AD}$, pode-se observar que expressões diversas descrevem as expressões faciais e essas descrições não se repetem muito. A maior repetição de expressão identificada foi "franze a testa" (2 vezes) e "com a testa franzida" que ocorre uma vez. Dentre os aspectos da face, além da "testa" (3), o foco da descrição também recai nos "olhos" (3). Os verbos que se destacam na descrição das expressões faciais do filme analisado são: "enruga" (2), "comprime" (2) e "franze" (2).

O estudo mostra que as escolhas lexicais reforçam o conflito do filme, pois poucas vezes estão relacionadas a contextos alegres, dando maior ênfase à tensão e à atitude reflexiva das personagens. Dessa forma, é possível relacionar tais escolhas com o gênero drama, uma vez que se prima pelo conflito entre as personagens.

As estruturas discursivas mais recorrentes desta categoria analisada podem ser resumidas conforme o Quadro 5.

Quadro 5 - Estruturas discursivas mais recorrentes para a etiqueta $<$ PERS_EXPFAC $>$

\begin{tabular}{|l|}
\hline \multicolumn{2}{|c|}{ SENTENÇA COMPLEXA com COORDENADA ADITIVA: } \\
VERBO + OBJETO DIRETO (substantivo)
\end{tabular}




\title{
SENTENÇA SIMPLES
}

ADJUNTO ADVERBIAL (expressão preposicionada) + SUJEITO (substantivo ou pronome pessoal) + VERBO

\section{Exemplo:}

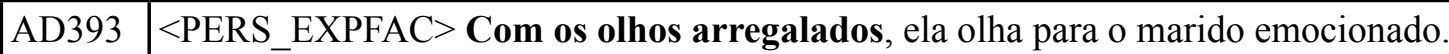

\author{
SENTENÇA SIMPLES ou SENTENÇA COMPLEXA \\ com COORDENADA ADITIVA OU SUBORDINADA. \\ SUJEITO (substantivo) + VERBO + COMPLEMENTO \\ (objeto direto ou adjunto adverbial)
}

ou

VERBO + COMPLEMENTO (advérbio ou expressão)

\section{Exemplos:}

AD250 1 De quatro, Rob $<$ PERS_EXPFAC $>$ coloca a língua pra fora e balança o quadril.

AD382 2 Pensativa, Nícola $<$ PERS_EXPFAC $>$ esboça um sorriso.

AD221 Rob encara Nícola, que o olha $<$ PERS_EXPFAC $><$ PERS_EEMOC $>$ suplicante.

Fonte: Elaborado pelas autoras deste artigo.

A primeira estrutura esquematizada no Quadro 5 é a mais frequente no roteiro estudado, com quatro ocorrências. A partir dela, percebe-se que do total de etiquetas de expressões faciais um número significativo constitui o centro da ação da personagem, de modo que a estrutura é composta por um verbo, seguido de determinada parte do rosto afetada. No exemplo apresentado, a elipse do sujeito atribui maior destaque ao verbo, tornando-o o tema da sentença. Dessa forma, como em alguns exemplos das indicações de estado emocional e mental, trata-se de uma tendência à tematização, pois há mudança na estrutura mais tradicional da sentença: SUJEITO + VERBO + COMPLEMENTO.

O recurso da tematização é também observado na segunda estrutura discursiva descrita no Quadro 5. Nesse caso, trata-se de um adjunto adverbial, que passa a ser tema da mensagem. Vale ressaltar que essa segunda estrutura mais encontrada (três ocorrências) é na verdade uma variante da anterior, trocando o verbo de ação por um adjetivo. Com efeito, a expressão "com os olhos arregalados" poderia ser transformada em "arregalando os olhos". O interesse em se realizar essa mudança hipotética está em evidenciar que, como na primeira estrutura, continua-se tratando de uma ação da face, só que esta se apresenta na forma de adjetivo.

A diferença entre a última estrutura descrita no Quadro 5 e as anteriores é que as expressões faciais, apesar de relevantes, não estão em destaque e, portanto, não sofrem tematização, seguindo-se, desta forma, a estrutura tradicional da sentença. Mais uma vez, percebe-se que a expressão facial costuma ser transmitida por meio de verbo de ação em relação a uma parte do rosto (AD250 e AD382) ou com um adjunto adverbial que modifica o verbo (AD221).

Diante do exposto, no Quadro 6 apresenta-se uma reflexão comparativa de uma inserção de $\mathrm{AD}$ referente à expressão facial e sua respectiva imagem. Na cena em questão, utiliza-se da sequência plano/contraplano, que favorece cenas de conversas com cargas emotivas. Além disso, alternam-se dois primeiros planos, o que também favorece esse tipo de informação. 
Quadro 6 - Comparação quadro a quadro entre as imagens do filme e a AD248

CONTEXTO: Esta sequência acontece no período preparatório para a adoção do cachorro Thomas. Quando os pais voltam da casa onde nasceu o filhote, eles decidem preparar psicologicamente o filho para a convivência com um cão. O pai empreende uma conversa com Kyle, tentando retratar possíveis reações do animal. Rob inicia falando da expressão de sorriso do "rosto" do trem Thomas, brinquedo predileto de Kyle. Rob explica que um sorriso é sinal de felicidade e que, assim como as personagens, as pessoas também expressam sua felicidade rindo. Ele imita uma risada, sob o olhar sério do filho. $\mathrm{Na}$ cena analisada em seguida, Rob prossegue fazendo uma expressão de raiva e explica que isso acontece quando as pessoas estão "bravas". Kyle oferece o mesmo olhar sério. Na cena seguinte, o pai chega então a falar que cachorros também se aborrecem e imita um rosnar de cachorro.

\begin{tabular}{|c|l|}
\hline IMAGEM & \multicolumn{1}{|c|}{ ROTEIRO DE AD } \\
\hline (Plano fechado) & \\
\hline \\
\hline
\end{tabular}

Fonte: Elaborado pelas autoras deste artigo.

Como se pode perceber pelo contexto, a expressão facial nessas duas imagens sucessivas (Quadro 6, AD248) é absolutamente necessária para o desenrolar da trama. Não surpreendente, então, que haja tematização do verbo, pela elipse do sujeito. Essa informação foi considerada tão relevante que, mesmo a imagem sendo um plano/contraplano do pai e do filho, a AD optou por se deter na expressão 
facial do pai, por meio de sentenças coordenadas, omitindo a reação séria do menino. Essa omissão também se deve ao pouco tempo disponível para a audiodescrição, já que a fala do pai recomeça logo em seguida.

\section{DISCUSSÃO DOS RESULTADOS}

A narrativa em análise tem como foco um drama familiar construído a partir da relação entre o casal (Nícola e Rob) e da relação dos dois com o filho autista Kyle, o que pode ser motivo da preponderância de etiquetas dessas personagens, no campo de descrição de sentimentos.

Observa-se que, das 51 etiquetas de estado emocional identificadas na análise, 48 etiquetas $<$ PERS_EEMOC $>$ descrevem as personagens que integram esse núcleo familiar; das 23 etiquetas de estado mental, 21 etiquetas $<$ PERS_EMENT $>$ descrevem os pais e a criança, assim como todas as etiquetas verificadas para a descrição das expressões faciais $<$ PERS_EXPFAC $>$ focam nas três protagonistas. As personagens secundárias têm suas emoções descritas 03 vezes, enquanto seus estados mentais são traduzidos apenas 02 vezes.

Ao analisar as descrições dos sentimentos das protagonistas, percebe-se que o filme audiodescrito traça um perfil mais emotivo para Nícola (mãe) e mais racional para Rob (pai). Nesse sentido, predominam na descrição de Nícola as etiquetas de estado emocional $<$ PERS_EEMOC $>$ e na de Rob as etiquetas de estado mental $<$ PERS_EMENT $>$. Identifica-se uma tendência do filme a obedecer a estereótipos do que sejam características femininas e masculinas, estereótipos estes próprios do gênero melodramático, superando, portanto, as características do simples drama.

Com relação ao menino Kyle, verifica-se que sua condição de autista mostrada nas imagens se projeta no roteiro da AD. Assim, apesar da centralidade do garoto na trama, a caraterização verbal de seus sentimentos é mais escassa e uniforme (sem variações de escolhas lexicais), o que aparentemente faz sentido, pois sendo ele autista, possui algumas restrições e dificuldades para expressar seus sentimentos.

No nível gramatical-discursivo (JIMÉNEZ HURTADO, 2010), percebe-se na estrutura das inserções mais recorrentes aqui analisadas que há uma nítida tendência à inversão de termos da oração, colocando em destaque as informações sobre sentimentos das personagens.

Mesmo permanecendo apenas no campo das emoções, os dados coletados apontam para a existência de um paralelismo entre os signos visuais da obra e os signos verbais do roteiro de $\mathrm{AD}$, confirmando a natureza multimodal do filme audiodescrito. Nota-se que a caracterização dos sentimentos das personagens se dá conforme o que é enfocado na narrativa visual, ou seja, os traços narratológicos do audiovisual se refletem no roteiro de AD, conforme Jiménez Hurtado (2010).

Corroborando Mascarenhas (2012), este estudo dá indícios de que o gênero fílmico influencia nas escolhas discursivas do roteiro de AD. O filme $U m$ Amigo Inesperado, ao enfocar um drama familiar, possui um apelo emotivo forte, a partir do envolvimento sentimental entre os personagens, que impulsiona as ações dramáticas de toda a narrativa. Parte da recriação do gênero drama neste filme é identificada, portanto, nas 87 descrições de personagens ligadas à expressão de sentimentos, distribuídas no total de 510 inserções de $\mathrm{AD}$, o que corresponde a $17,05 \%$ das inserções com esse tipo de informação. Isso representa um percentual significativo para a tradução dos efeitos programados presentes na obra, ou seja, os elementos narrativos estruturantes para a construção de expectativa na audiência, no caso, a comoção, o choro, a empatia etc.

\section{CONSIDERAÇÕES FINAIS}

Este trabalho descreveu e discutiu as estratégias de tradução na AD do filme Um Amigo Inesperado, usadas para reconstruir os sentimentos expressos pelas personagens. Para tanto, realizou-se uma análise em nível discursivo e narratológico do roteiro de $\mathrm{AD}$, em comparação com a linguagem imagética do filme. Para dar suporte à descrição e à discussão, os dados foram coletados e tratados por meio da linguística de corpus. Essa metodologia permitiu levantar, por exemplo: o número de ocorrências das estratégias de tradução, o contexto de utilização e sua a distribuição no corpus. Em termos lexicais, pôde-se observar quais palavras foram mais frequentes no roteiro e como foram utilizadas. 
Verificou-se a adequação da linguística de corpus para as finalidades propostas, com o auxílio do programa Wordsmith Tools 6.1, conforme já demonstrado anteriormente pela equipe do projeto CAD_TV, em trabalhos como o de Nóbrega (2015) e Seoane (2015).

Como resultado deste trabalho, verificou-se que a estratégia discursiva predominante na $\mathrm{AD}$ do filme analisado é a inversão da ordem clássica da sentença, colocando-se palavras ou expressões utilizadas para explicitar os sentimentos das personagens em início de oração, adiante do sujeito e do verbo. Com relação aos aspectos narratológico e imagético, pode-se observar que existe uma relativa correspondência entre o texto verbal da $\mathrm{AD}$ e o texto multimodal do filme. De uma forma geral, a construção da narrativa fílmica, por meio de enquadramentos e sequência, foi simultaneamente traduzida na narração verbal, por meio de inversão dos elementos da sentença e de emprego de léxico relativo ao campo dos sentimentos.

Também foram encontrados elementos da caracterização do gênero fílmico drama e até do melodrama na $\mathrm{AD}$ do filme estudado, principalmente na ênfase dos aspectos emocionais e na caracterização das personagens, como estereotipadas desses gêneros. Esse aspecto da discussão corroborou as hipóteses colocadas em estudo anterior por Mascarenhas (2012).

Por serem os resultados aqui apresentados apenas iniciais, fica a proposta de replicar ou ampliar a análise a um corpus maior, ou a um corpus de gênero filmico diferente, com a finalidade de perceber se os resultados se repetem ou são divergentes. Com efeito, os resultados abrem espaço para se aprofundar a influência do gênero narrativo na AD de filmes e o cotejo da AD com suas respectivas imagens.

\section{REFERÊNCIAS}

AUMONT, Jacques; MARIE, Michel. Dicionário teórico e crítico do cinema. Tradução de Carla Bogalheiro Gamboa e Pedro Elói Duarte. Lisboa: Edições Texto \& Grafia, 2008.

BARBOSA, Gustavo. Dicionário de Comunicação. Rio de Janeiro: Elsevier, 2001.

BRASIL. Ministério das Comunicações. Portaria no 188, de 24 de março de 2010. Altera a redação da Norma Complementar $n^{\circ} 01 / 2006$ - Recursos de acessibilidade, para pessoas com deficiência, na programação veiculada nos serviços de radiodifusão de sons e imagens e de retransmissão de televisão, aprovada pela Portaria $\mathrm{n}^{\circ} 310$, de 27 de junho de 2006. Brasília, DF, 2010. Disponível em: <http://www.mc.gov.br/index.php?option=com_content $\&$ view $=$ article\&id $=26611 \&$ catid $=273>$. Acesso em: 05 jun. 2014.

CASTILHO, Ataliba T. de. Nova gramática do português brasileiro. São Paulo: Contexto, 2014.

FERREIRA, Susana da Costa. O professor como personagem e a escola como cenário: escola e sociedade em filmes norte-americanos (1955-1974). 2003. 210f. Tese (Doutorado em História) - Programa de Pós-Graduação em História da Universidade Federal do Paraná (UFPR), Curitiba, 2003.

GROSVENOR, Carrie. Description of film genres. Drama definition. Disponível em: $<$ http://movies.lovetoknow. com/wiki/History_of_Comedy_Films>. Acesso em: 21 jan. 2016.

JAKOBSON, Roman. Linguística e comunicação. São Paulo: Cultrix, 1995.

JIMÉNEZ HURTADO, Catalina. Fundamentos teóricos del análisis de la AD. In: JIMÉNEZ HURTADO, Catalina; RODRÍGUEZ, Ana; SEIBEL, Claudia (Org.). Un corpus de cine: teoría y práctica de la audiodescripción. Granada: Tragacanto, 2010. p. 13-56.

Una gramática local del guión audiodescrito. Desde la semántica a la pragmática de un nuevo tipo de traducción. In: . Traducción y accesibilidad. Subtitulación para sordos y audiodescripción para ciegos: nuevas modalidades de traducción audiovisual. Frankfurt: Peter Lang, 2007. p. 55-80.

MELO, Matheus de Oliveira. A poética das lágrimas: o melodrama no cinema norte-americano clássico. 2005. 44f. Monografia (Bacharelado em Jornalismo) - Universidade Federal da Bahia (UFBA), Salvador, 2005.

MASCARENHAS, Renata de Oliveira. A audiodescrição da minissérie policial Luna Caliente: uma proposta de tradução à luz da narratologia. 2012. Tese (Doutorado em Letras e Linguística) - Universidade Federal da Bahia (UFBA), Salvador, 2012. 
NÓBREGA, Ana Carla Ponte. A construção dos ambientes nos roteiros de audiodescrição dos filmes de animação Up - Altas Aventuras e Megamente: um estudo baseado em corpus. 2015. Trabalho de Conclusão de Curso (Graduação em Letras - Inglês) - Universidade Estadual do Ceará (UECE), Fortaleza, 2015.

PAYÁ, Maria Pérez. Recorte de cine audiodescrito: el lenguaje cinematográfico em Tagetti Imagen y su reflejo en la audiodescripción. In: JIMÉNEZ HURTADO, Catalina; RODRÍGUEZ, Ana; SEIBEL, Claudia (Org.) Un corpus de cine: teoría y práctica de la audiodescripción. Granada: Tragacanto, 2010. p. 13-56.

PLAZA, Júlio. Tradução intersemiótica. São Paulo: Perspectiva, 2013.

PROJETO CAD_TV. Acessibilidade na televisão brasileira: a construção e a análise de um corpus de roteiros de audiodescrição da grade de programas da TV aberta. Pesquisadoras responsáveis: Renata de Oliveira Mascarenhas e Vera Lúcia Santiago Araújo. Universidade Estadual do Ceará, 2013.

SALWAY, A. A corpus-based analysis of audio description. In: DIAZ CINTAS, J.; ORERO, P.; REMAEL, A. (Ed.). Media for All - subtitling for the deaf, audio description, and sign language. New York: Rodopi, 2007. p. 151-174.

SEOANE, Alexandra Frazão. A descrição das características físicas dos personagens nos filmes audiodescritos exibidos pela Rede Globo um estudo baseado em corpus. 2015. Trabalho de Conclusão de Curso (Graduação em Letras - Inglês) - Universidade Estadual do Ceará (UECE), Fortaleza, 2015.

SILVA, Osmina Maria Marques da. A audiodescrição dos personagens de filmes: um estudo baseado em corpus. 2012. Dissertação (Mestrado em Linguística Aplicada) - Universidade Estadual do Ceará (UECE), Fortaleza, 2012.

UM AMIGO inesperado. Direção: Simon Shore. Produção: Beryl Vertue e Elaine Cameron. Intérpretes: Keeley Hawes; Bem Miles; Andrew Byrne. Duração: 93 min. Londres: Centauro, c2006. 